\title{
Stenting of venous bypass grafts: A new treatment modality for patients who are poor candidates for reintervention
}

Ivan K. de Scheerder, MD, ${ }^{a}$ Bradley H. Strauss, MD, ${ }^{a}$ Pim J. de Feyter, MD, ${ }^{a}$ Kevin J. Beatt, MB, BS, ${ }^{a}$ Leo H. B. Baur, MD, ${ }^{b}$ William Wijns, MD, ${ }^{c}$ Guy R. Heyndrix, MD, ${ }^{d}$ Harry Suryapranata, MD, ${ }^{a}$ Marcel van den Brand, MD, ${ }^{a}$ Beerd Buis, MD, ${ }^{b}$ and Patrick W. Serruys, MD, ${ }^{a}$ with the technical assistance of Marie-Angele M. Morel ${ }^{\mathrm{a}}$ and Eline Montauban van Swijndregt. ${ }^{a}$ Rotterdam and Leiden, The Netherlands, and Brussels and Aalst, Belgium

Patients first seen with medically refractory anginal symptoms after saphenous vein bypass surgery pose a difficult problem for cardiologists and cardiovascular surgeons. These patients are generally older, with more extensive, diffuse disease involving the native coronary arteries and venous bypass grafts. Repeat coronary artery bypass graft surgery (CABG) for recurrent ischemia is technically more difficult, is associated with a higher mortality and morbidity, and has inferior long-term clinical results when compared with a first bypass operation. ${ }^{1-3}$ Conventional balloon angioplasty offers an alternative mode of revascularization in selected patients. The immediate results of this procedure have been shown to be favorable in patients with discrete lesions in venous bypass grafts but considerably less satisfactory in diffusely diseased, ulcerated, or thrombosed venous grafts. ${ }^{4-6}$ Furthermore, it appears that the rate of restenosis is high, varying from $40 \%$ to $70 \%$ depending on the site of the lesions in the graft and the overall extent of disease in the conduit. ${ }^{7-13}$

From the Thoraxcenter, University Hospital Rotterdam, ${ }^{a}$ University Hospital Leiden, ${ }^{b}$ University Hospital Saint Luc, ${ }^{,}$and O. L. V. Hospital. ${ }^{d}$

Supported by a grant from the Dutch Ministry of Science and Education, The Hague, The Netherlands (87159), a research fellowship from the Heart and Stroke Foundation of Canada (Dr. Strauss), and a research fellowship from the British and Netherlands Heart Foundation (Dr. Beatt).

Received for publication $\Lambda$ ug. 2, 1991; accepted Sept. 20, 1991.

Reprint requests: P. W. Serruys, Thoraxcenter, Catheterization Laboratory, Erasmus University Rotterdam, PO Box 1738, 3000 DR Rotterdam, The Netherlands.

4/1/35482
Stent implantation has been proposed as an alternative or adjunct to percutaneous transluminal coronary angioplasty (PTCA) for diseased venous bypass grafts. Results of early studies with small numbers of patients have shown that stents can be placed safely and successfully in bypass grafts with an encouraging low rate of restenosis. ${ }^{14-21}$ Therefore we initiated this observational study to assess the acute and late results of stent implantation in stenosed coronary artery bypass grafts in symptomatic patients with diffuse, extensive native coronary artery and bypass graft disease who are poor candidates for conventional balloon angioplasty or reoperation.

\section{METHODOLOGY}

Study population (Tables 1 and II). Between January 1988 and March 1990, a total of 136 stents were implanted in 69 patients ( 12 women and 57 men) in the four participating hospitals in The Netherlands and Belgium. The study protocol was approved by the ethics committees of the individual hospitals and informed consent was obtained from all patients. A senior investigator (P.W.S.) was present for all stent implantations.

The decision to implant a stent was reached after discussion between cardiologists and surgeons (Table III). Forty-two patients were considered inoperable because of either a high risk/benefit ratio related to repeat surgery $(n=28)$, unfavorable coronary vessel anatomy such as diffusely diseased distal vessels $(\mathrm{n}=4)$, poor left ventricular function (ejection fraction $<35 \%)(\mathrm{n}=6)$, or concurrent noncardiac risk 
Table I. Study population

\begin{tabular}{ll} 
No. of patients & 69 \\
No. of bypasses & 74 \\
No. of lesions & 95 \\
No. of stents & 136 \\
Ejection fraction $(\%)$ & $53.9(26-71)$ \\
Risk factors & \\
$\quad$ Hypercholesterolemia $>7 \mathrm{mmol} / \mathrm{L}$ & 26 \\
Hypertension & 15 \\
Smokers & 46 \\
Diabetes mellitus & 14 \\
\hline
\end{tabular}

Table II. Specific lesion characteristics

$\begin{array}{lc}\text { No. of bypasses } & 74 \\ \text { Age of bypass graft (mo) } & 83(1-166) \\ \text { Mean diameter of graft (mm) } & 3.3(1.6-7.0) \\ \text { Mean minimal lumen diameter (mm) } & 1.4(0-2.9) \\ \text { Length of stenosis (mm) } & 16.5(2-50)\end{array}$

factors $(n=4)$. Conventional coronary angioplasty was considered high risk in 39 patients because of the age of the grafts, the length of the stenosis, and/or unfavorable angiographic features (tandem lesions, eccentric lesions, lesions containing ulcers, aneurysms, calcifications, or dissections) (Figs. 1 to 4).

The mean age of the patients was 63 years (range 44 to 78 ), and the mean age of the implanted bypass grafts was 83 months (range 1 to 166). Forty-eight patients had at least one previous myocardial infarction, and eight had undergone more than one previous bypass procedure. Single-, double-, and triplevessel disease was present in $3 \%, 23 \%$, and $74 \%$ of the patients, respectively. Eleven patients were in New York Heart Association (NYHA) class II, 27 were in class III, and 29 were in class IV; in two paticnts the stents were implanted during evolving myocardial infarction. All patients had documented ECG evidence of ischemia.

The stent implantation data are presented in Table IV. A single stent was implanted in 30 patients, two stents in 24 patients, three stents in seven patients, four stents in five patients, five stents in one patient, and 6 stents in two patients. The stent was placed in single grafts in 25 patients and in sequential grafts in 44 . In five patients the stent was implanted into totally occluded vessels (during an evolving myocardial infarction in two and in chronic occlusions in three.

Implanted device. In the first 26 patients we used the Medinvent Wallstent (Medinvent, Lausanne,
Table III. Reasons for preferring stent implantation (categories are not mutually exclusive)

\begin{tabular}{lr}
\hline Patients not suitable or high risk for repeat CABG & 42 \\
Reasuns & 28 \\
High risk/benefit profile & 4 \\
Unfavorable coronary vessel anatomy & 6 \\
Poor left ventricular function (ejection fraction $<35 \%)$ & 4 \\
Concurrent noncardiac risk factors & 39 \\
Patients considered high risk for conventional PTCA & \\
Reasons & 32 \\
Long lesions (>15 mm) & 23 \\
Tandem lesions & 25 \\
Lesions containing ulcers & 17 \\
Dissections & 18 \\
Clot & 34 \\
Diffusely diseased bypass graft & 53 \\
Eccentric lesions & \\
\hline
\end{tabular}

Table IV. Stent implantation data

$\begin{array}{lc}\text { No. of stents } & 136 \\ \text { Mean diameter of stent (mm) } & 4.3(3.5-6.0) \\ \text { Position } & 7 \\ \text { Ostial } & 127 \\ \text { Shaft } & 4 \\ \text { Distal anastomosis } & \\ \text { Procedure type } & 30 \\ \text { Single stent-single lesion } & 90 \\ \text { Multiple stent-single lesion } & 16 \\ \text { Multiple stent-multiple lesion } & \end{array}$

Switzerland), and later we used the polymer-coated Medinvent Biogold stent. The stent consists of a stainless steel alloy with a self-expanding mesh design. ${ }^{15}$ The unconstrained length varied between 15 and $27 \mathrm{~mm}$, and its diameter in the fully expanded state was between 3.5 and $6.0 \mathrm{~mm}$ and was selected to be $0.50 \mathrm{~mm}$ larger than the reference diameter of the vessel.

After stent implantation the patients were monitored in the coronary care unit. The rigorous anticoagulation regimen has been described previously. ${ }^{22}$ All patients received aspirin the day before the procedure and intravenous heparin $(10,000$ IU) at the beginning of the procedure. Before stent implantation 10,000 IU heparin and $500 \mathrm{mg}$ dextran every 4 hours were given intravenously. Immediately after stent implantation 100,000 to 250,000 IU urokinase was infused into the coronary bypass graft via the guiding catheter. Intravenous heparin administration was continued at a minimum dosage of 24,000 $\mathrm{IU} / 24$ hours; the dosage was adjusted according to the activated partial thromboplastin time ( 80 to 120 

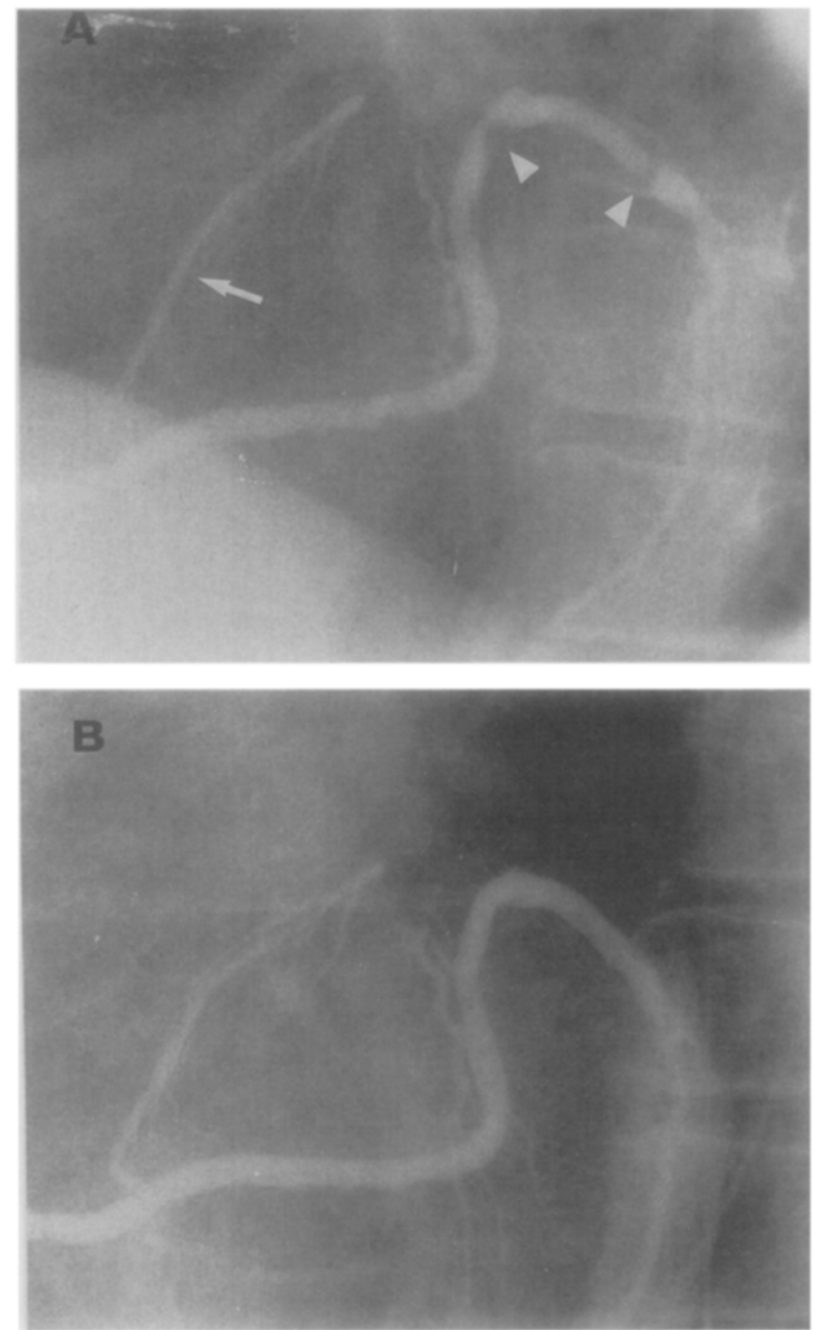

Fig. 1. Jump graft to left anterior descending artery ( $a r-$ row), then to first diagonal branch, and then to marginal branch. A, Two lesions in jump graft between diagonal and marginal branches (arrowheads). B, Immediate result after stenting. Distal end of stent may have extended into native coronary artery.

seconds). Oral acenocoumarol was started on the day of implantation. The heparin infusion was continued until the prothrombin time measured by thrombotest (Nycomed, Oslo, Norway) was lowered to 5\% to $10 \%$ for 2 subsequent days and discontinued slowly thereafter. After stent implantation the patients were also given aspirin ( $300 \mathrm{mg} /$ day), dipyridamole ( 300 to $450 \mathrm{mg} / \mathrm{day}$ ), and nifedipine ( 30 to $60 \mathrm{mg} /$ day), which in addition to the oral anticoagulant were maintained for 3 to 6 months after the pro-
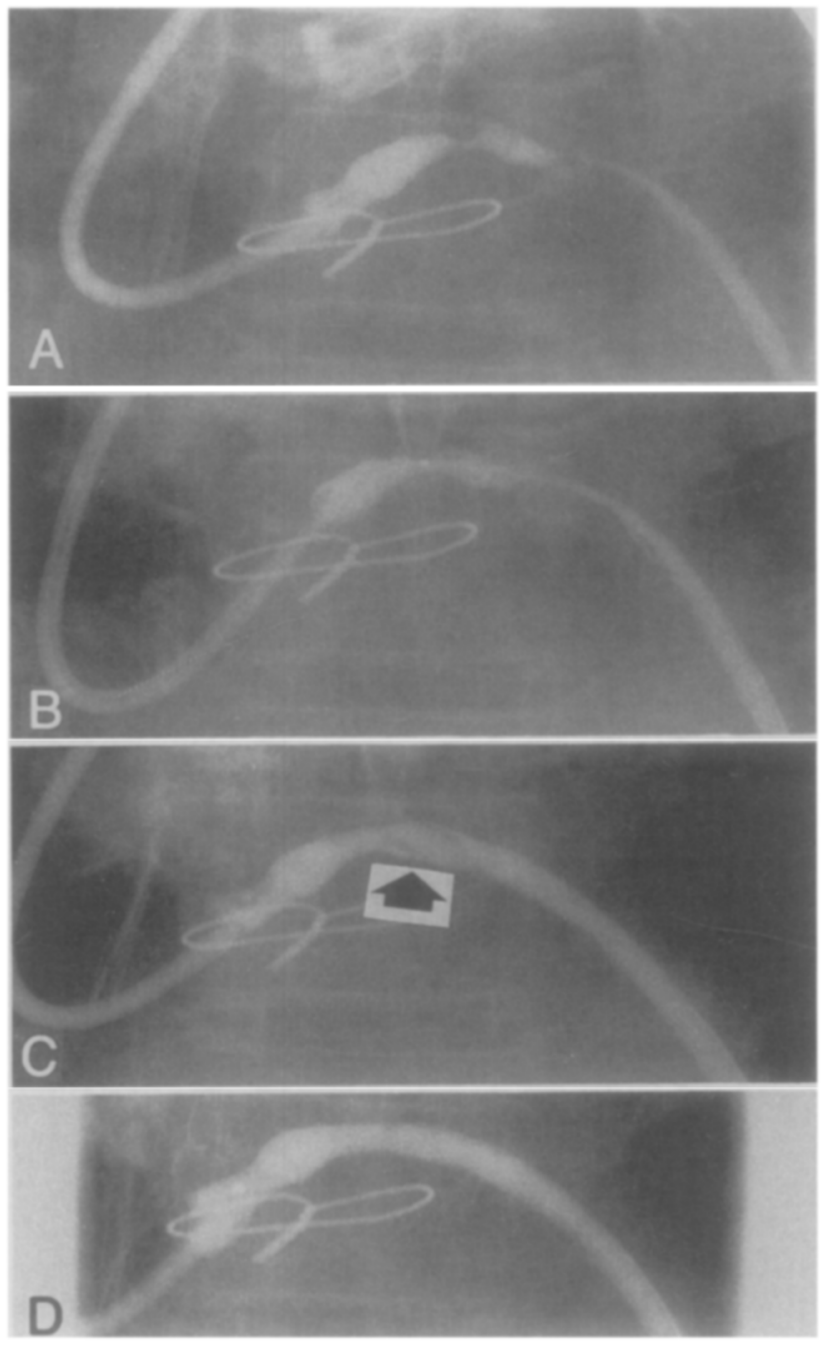

Fig. 2. Top panel, Two tandem lesions with aneurysm of bypass graft located proximal to first lesion. Second panel, Balloon angioplasty catheter in position across lesion. Balloon dilatation resulted in dissection. Third panel, After implantation of distal stent, intraluminal flap (arrow) is still evident in proximal lesion. Lower panel, After implantation of second stent in proximal lesion.

cedure. The patients were followed at our outpatient clinic at 1 and 3 months and underwent repeat coronary angiography 6 months after the initial procedure or earlier if symptoms recurred.

Quantitative coronary angiography. The quantitative analysis of the stenotic coronary segments was carried out with the computer-assisted Cardiovascular Angiography Analysis System (CAAS), which has been described in detail. ${ }^{23-28}$ The angiographic analysis was done before and after angioplasty, immedi- 

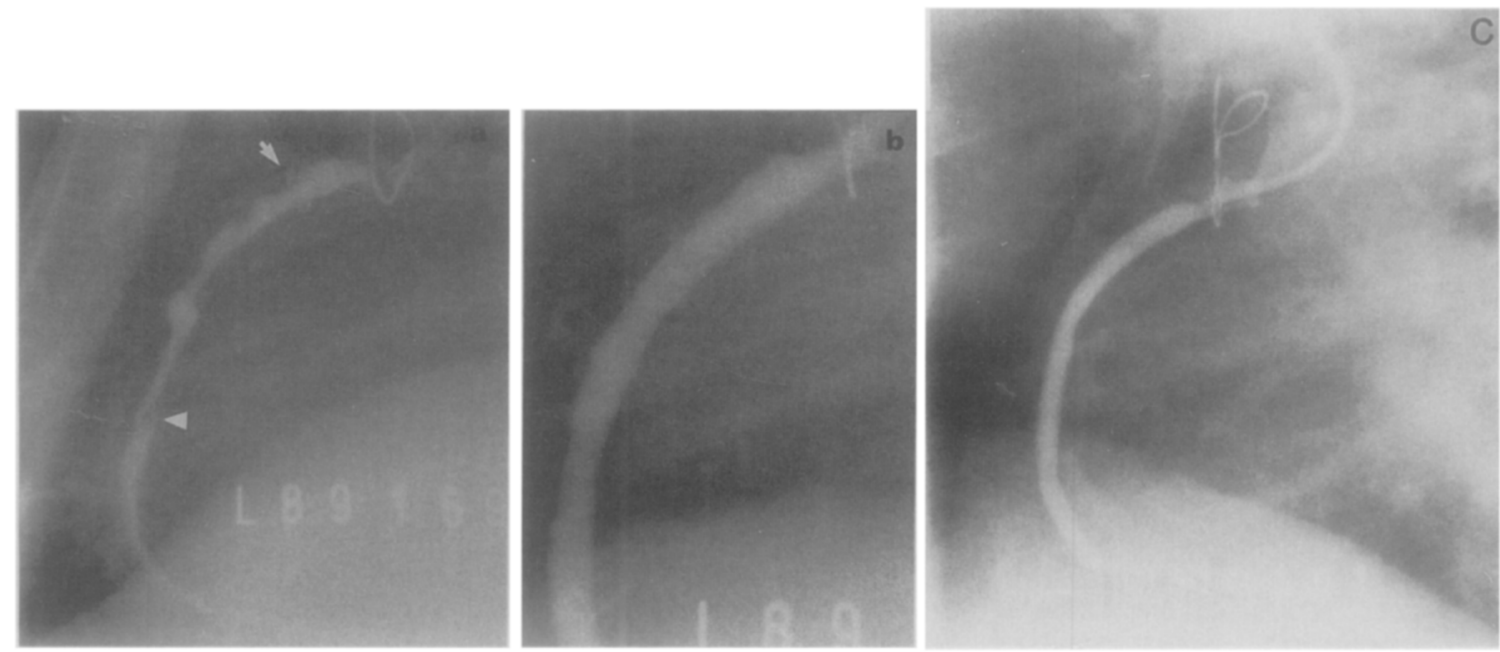

Fig. 3. A, Bypass graft to right coronary artery (7-inch image intensifier). Long segment bypass vessel is severely diseased with involvement of ostium and several complex features including ulceration in proximal aspect of graft (arrow) and intraluminal defect in midgraft (arrowhead). B, After placement of three stents (5-inch image intensifier). C, Six-month follow-up angiogram showing late excellent result.

ately after stent implantation, and at follow-up in all patients with the average of multiple matched views with orthogonal projections wherever possible.

Restenosis. Two different sets of criteria were applied to determine the rate of restenosis. We have found a change in minimal luminal diameter of 0.72 $\mathrm{mm}$ or more to be a reliable indicator of angiographic progression of vessel narrowing. ${ }^{23-25}$ This value takes into account the limitations of coronary angiographic measurements and represents two times the longterm variability for repeat measurements of a coronary obstruction by means of the CAAS. The other criterion for restenosis was an increase in the diameter of the stenosis (DS) from less than $50 \%$ after stent implantation to more than or equal to $50 \%$ at follow-up. This criterion was selected according to common clinical practice. ${ }^{29}$

\section{OBSERVATIONS}

Stent implantation procedure. All patients underwent successful stent implantation (DS $<50 \%$ immediately after placement of the stent). In two patients the initial stent was not optimally positioned and did not cover the entire lesion, so that an additional procedure was required to implant another stent to achieve an optimal result. Although no immediate major complications occurred during the procedure, two patients required intracoronary thrombolytic therapy because of distal embolization without subsequent elevation of the creatine kinase level. Three other patients had increases in the creatine kinase level $(<200$ IU).

In-hospital complications. Acute thrombotic events in the stent occurred in seven patients $(10 \%)$. One of these occlusions was related to cessation of anticoagulation treatment. This patient (considered inoperable) had a severe retroperitoneal hematoma 7 days after stent implantation, which necessitated discontinuation of the anticoagulation therapy. Thirty days after implantation the patient had an acute myocardial infarction, leading to cardiogenic shock and death. One patient, who had the stent implanted during an evolving myocardial infarction, had an acute thrombotic closure of the stented vessel 1 day after stent implantation. The resulting myocardial infarction was treated conservatively.

Two other patients, who had unstable angina pectoris and angiographic defects consistent with thrombi, had acute thrombotic occlusions and myocardial infarctions 7 and 12 days after stent implantation, respectively. One of these patients, who was treated conservatively, died suddenly 6 months after implantation, having remained stable with mild angina pectoris. The other patient underwent CABG after emergent reopening of the vessel during repeat PTCA. The last thrombotic occlusion occurred 1 day after implantation in one of the patients with stent implantation after recanalization of a chronically occluded graft. This patient was referred for repeat CABG. 


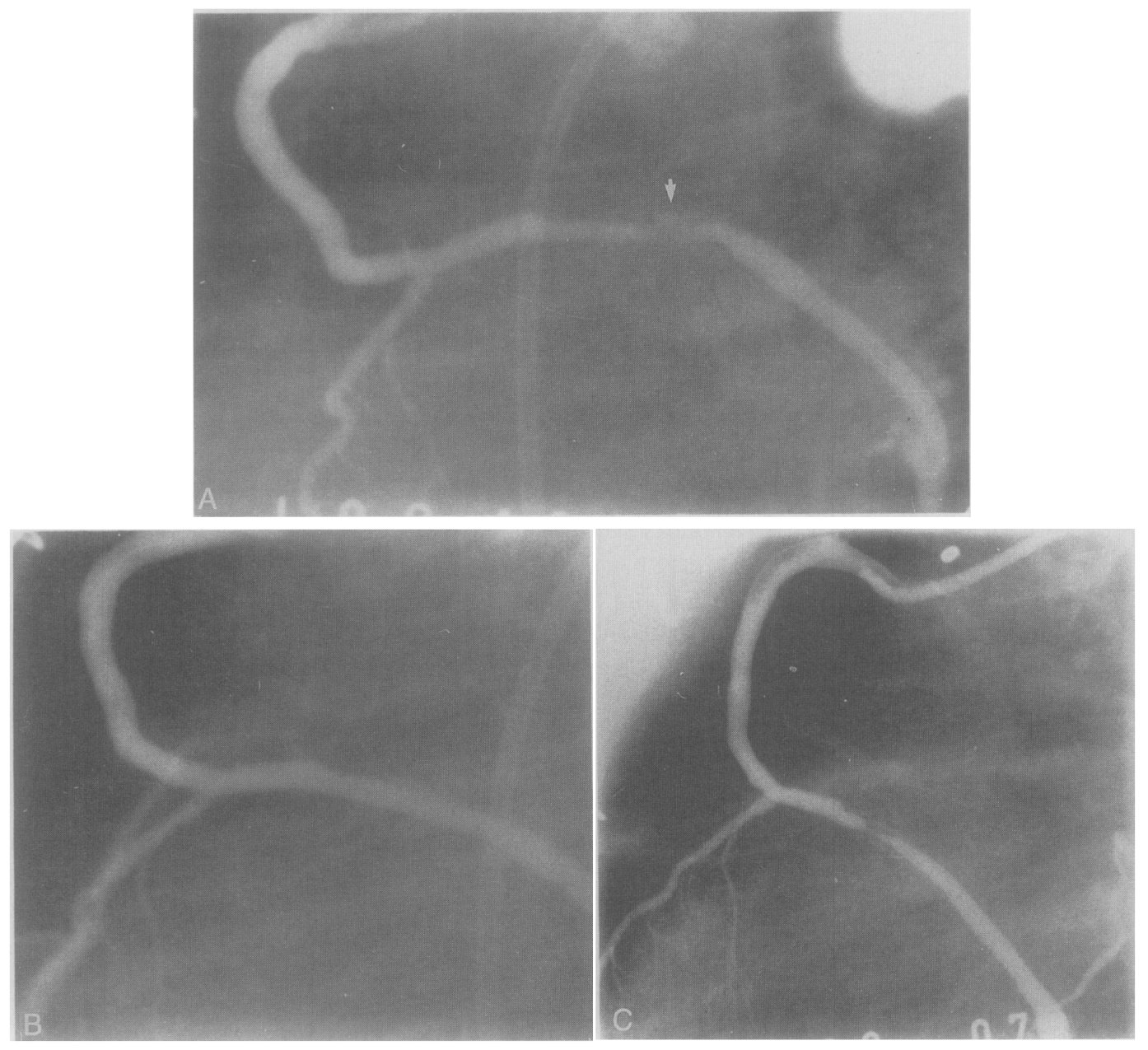

Fig. 4. A, Complex lesion with ulceration (arrow) in jump bypass graft before stenting. B, Immediate result after stenting. C, Six-month follow-up angiogram showing restenosis within stent. Outline of stent is faintly visible.

Two patients had unstable angina pectoris 3 and 10 days after stent implantation, which was related to an angiographically visible but nonocclusive thrombus. In one patient this thrombus was related to cessation of anticoagulation 6 days after the procedure as a result of Mallory-Weiss syndrome with persistent gastrointestinal bleeding. ${ }^{30}$ Because of symptomatic recurrent ischemia, the patient was sent for surgery. The second patient, who had been treated for unstable angina pectoris, had resting angina pectoris 1 day after implantation of two stents. Angiography revealed a partially occlusive thrombus between the two stents and another stent was placed between the two previous stents. The following day resting angina pectoris recurred and the patient was treated surgically.
Bleeding complications occurred in 23 patients $(33 \%)$. Two patients had fatal intracranial bleeding, one patient had a retroperitoneal hematoma, and two patients had gastric bleeding. An additional 18 patients had hematomas at puncture sites requiring blood transfusions, and seven of these patients required surgical repair of a false aneurysm. Bleeding complications were associated with a considerably longer hospital stay - 18 days in comparison to 7 days when the postimplantation course was uneventful.

Discharge status. Stent implantation resulted in complete relief of angina pectoris (NYHA class I) in 45 patients $(64 \%)$. Ten patients $(14 \%)$ still had mild symptoms (NYHA class II) after stent implantation (NYHA class II), and five patients (7\%) remained in NYHA class III. Four of these patients were consid- 
ered inoperable and the fifth was referred for reoperation.

\section{Long-term follow-up}

Angiography. In $53(90 \%)$ of the 59 patients with successful stenting and no major in-hospital complications, follow-up angiography was performed at $4.9 \pm 3.4$ months. Of the remaining six patients without angiographic follow-up, five refused to undergo control angiography, and in another patient the implantation film was technically inadequate for analysis, although no significant restenosis was seen at follow-up.

In the overall group the mean minimal luminal diameter increased significantly from $1.4 \pm 0.82$ to $2.7 \perp 0.7 \mathrm{~mm}(p<0.001)$ and the diameter stenosis decreased significantly from $58 \pm 15 \%$ to $24 \pm 9 \%$. However, at late follow-up (including occlusions) there was a significant reduction in the mean minimal luminal diameter to $1.9+1.1 \mathrm{~mm}(p<0.001)$ and a significant increase in the diameter of the stenosis to $43 \pm 30 \%(p<0.001)$.

The incidence of restenosis depended on the definition. According to the criterion of a change in minimal luminal diameter of $0.72 \mathrm{~mm}$, detectable angiographic narrowing occurred within the stent in 25 patients $(47 \%)$. An increase in the diameter of the stenosis to $50 \%$ at follow-up was seen in 21 patients $(40 \%)$ and immediately adjacent to the stent in four patients $(7 \%)$. Stent occlusion was found in three of these patients.

Clinical follow-up. In the group of patients with angiographic restenosis (diameter stenosis $>50 \%$ criterion) $(\mathrm{n}=25), 19$ patients had a recurrence of angina pectoris necessitating reintervention (repeat PTCA, $n=10$; atherectomy, $n=2$; repeat $C A B G$, $\mathrm{n}=7$ ). Three of the patients who underwent surgery died during the postoperative period.

In the group without restenosis $(\mathrm{n}=28), 15$ patients had a recurrence of significant angina pectoris within 1 to 24 months after stent implantation. Ten patients underwent further intervention. In six a second stent was implanted in either the same or another bypass graft. Three patients underwent PTCA of one or more native vessels and one patient had repeat bypass surgery. The five remaining patients were treated medically. One patient without significant restenosis at the 6-month angiography died suddenly 500 days after stent implantation.

\section{COMMENTS}

The management of recurrent ischemia in patients who have had previous bypass surgery presents a se- rious and growing problem. Symptoms of myocardial ischemia recur or progress in approximately $5 \%$ of patients per year, ${ }^{3,26,27}$ and after 5 years up to $25 \%$ of vein grafts are occluded and $25 \%$ may show stenoses greater than $70 \% .{ }^{28}$ Reoperation is technically more complicated to perform and is generally associated with a higher mortality and morbidity than a primary operation and achieves symptomatic relief in only $60 \%$ to $70 \%$ of patients as compared with the $80 \%$ to $90 \%$ success rate after primary operations. 'The perioperative myocardial infarction rate varies among surgical groups between $2.0 \%$ and $11.5 \%$. The mortality rate after repeat bypass surgery ranges from $1.2 \%$ to $12.5 \% .^{1-3}$ Conventional balloon angioplasty has reported angiographic success rates of $75 \%$ to $100 \%$ for bypass grafts, ${ }^{7-13}$ with complications rates similar to angioplasty in native vessels. However, restenosis appears to occur more frequently with rates as high as $46 \%$ reported for proximal sites. 24,27

The majority of our patients were considered high risk for surgery or repeat PTCA. Inasmuch as all of these patients had severe symptoms in spite of maximal medical therapy, it was decided to try to attempt stenting of the angina-related bypass graft, although in some cases it was clear that full relief could not be expected because of diffuse native vessel disease that prohibited additional intervention. Most of the procedures were done without surgical standby. Since the introduction of stenting of stenosed saphenous bypass grafts in our institution in 1988, a total of 69 patients have been treated successfully with this new intervention compared with only 84 patients who underwent conventional angioplasty for stenosed saphenous bypass grafts during the period 1980 to 1988 . This new treatment modality has significantly expanded our therapeutic options in this particular patient group.

Our results show that stenting bypass grafts is technically feasible with excellent immediate results. Two advantages of the Wallstent for use in bypass grafts are (1) the length of the stent can be selected up to $25 \mathrm{~mm}$ for long lesions and (2) the self-expanding property appears to be an effective splint to tack back friable, protuberant atheromatous material and minimize embolization into the native coronary circulation. In 30 patients the stent was implanted directly without prior balloon dilatation for lesions that appeared high risk for embolization. No increase in creatine kinase levels was documented in this group of procedures.

Several important lessons emerge from this study. 
First, the majority of stent occlusions occurred in patients with acute ischemic syndromes (myocardial infarction or unstable angina pectoris with angiographic evidence of thrombi). The combination of thrombi during evolving myocardial infarction and unstable angina and the implantation of intracoronary stents seems to be highly thrombogenic leading to further thrombus formation and acute occlusion of the stent. Therefore we now carefully select our patients and when the diagnostic angiogram suggests the presence of intravascular clots, the patients are treated with intravenous heparin $(25,000 \mathrm{IU} / 24 \mathrm{hr})$ for 1 week before stent implantation. Although improved patient selection should decrease the occurrence of acute stent closure, it will remain an unpredictable event as evidenced by stent occlusion in one patient who was optimally anticoagulated and without the previously described risk factors. Furthermore, the timing of stent occlusion is also unpredictable (between 2 and 12 days), which complicates discharge planning decisions. Second, a meticulous anticoagulation schedule must be followed with frequent monitoring to minimize bleeding complications. As our experience evolved, bleeding and occlusion problems were encountered much less frequently and as a result, sulphinpyrazone was withdrawn because of a lack of evidence of its efficacy in the prevention of acute closure. Special care must also be given to insertion and removal of the femoral arterial sheath, since this accounted for the majority of bleeding complications. In particular, removal of the sheath $>12$ hours after implantation was associated with increased vascular complications. During the last 15 stent implantation procedures, no thrombolytic agents were administered leading to a considerable decrease in bleeding problems in the groin. Furthermore, oral coumadin was started the day before stent implantation leading to a quicker optimalization of the oral anticoagulation therapy, which made a shorter hospital stay possible.

The stent-related restenosis rate $(47 \%)$ seems to be comparable to that in historical studies of conventional angioplasty in venous coronary bypass grafts. ${ }^{4,5,30}$ However, these comparisons may not be valid since our population consisted of patients who were less than suitable candidates for conventional angioplasty. Earlier reports from Lausanne suggested a much lower restenosis rate $(9 \%)$ in lesions implanted with the Medinvent stent in bypass grafts. ${ }^{17,32}$ However, these differences may be the result of either differences in selection criteria, methods of angiographic assessment (quantitative vs visual estimation), or both.
Frequent reintervention in our study group was required because of restenosis or progression of disease in other lesions, a problem similar to that encountered with conventional angioplasty in bypass grafts. Three recent reports have been published on the late clinical follow-up of patients with conventional angioplasty in bypass grafts. The Thoraxcenter reported that only $41 \%$ of patients were alive and event free (myocardial infarction, repeat CABG, repeat PTCA) at a median follow-up period of 2.1 ycars. ${ }^{4} \mathrm{~A}$ review of the overall Dutch experience also showed limited late beneficial results with 2 -year and five-year event-free survival rates of $52 \%$ and $26 \%$, respectively, in 454 bypass patients. ${ }^{5}$ Webb et al. ${ }^{31}$ have described a $71 \%$ freedom from death, infarction, and surgery at 5 years in bypass patients who underwent PTCA at their institution but did not include the $27 \%$ incidence of second angioplasty procedures also required in their patient group. It is clear that stenting and angioplasty are only short-term solutions and do not affect the underlying problems of progressive graft atherosclerosis and iatrogenically induced restenosis.

Conclusions. Patients with severe coronary artery disease and previous bypass surgery who have.refractory symptoms as a result of progression of disease in the bypass graft comprise a difficult challenge to the physician. In patients who are poor surgical risks and unsuitable candidates for balloon angioplasty because of unfavorable anatomy, coronary stenting with the Wallstent can be performed successfully and offers an alternative therapy. However, stent implantation remains complicated by acute thrombotic occlusion and bleeding complications associated with the intense anticoagulation. The early benefits of stenting may be mitigated by the progression of disease in bypass grafts and iatrogenic induced restenosis. Stenting should be considered a palliative procedure in medically refractory patients with coronary bypass graft disease.

\section{SUMMARY}

During a 2-year period, 136 self-expanding Wallstents were implanted in saphenous vein bypass grafts in 69 patients with end-stage coronary artery disease. All patients had severe symptoms and the majority were poor candidates for either repeat surgery or conventional bypass coronary angioplasty because of unfavorable native anatomy, impaired left ventricular function, or a high-risk bypass lesion anatomy for coronary angioplasty. All procedures were technically successful without major complications and a need for emergency bypass surgery. 
However, during the hospital stay acute thrombotic complications occurred in seven patients $(10 \%)$ resulting in one death and acute myocardial infarction in five patients and necessitating emergency repeat PTCA in two patients and repeat CABG in four. Twenty-three patients had serious hemorrhagic complications directly related to the rigorous anticoagulation schedule. Two patients died of fatal cerebral bleeding. During follow-up, another five patients died accounting for a total mortality rate of $12 \%$. At late angiographic follow-up $(4.9 \pm 3.4$ months, $\mathrm{n}=53), 25$ patients $(47 \%)$ had a restenosis $(\geq 50 \%$ DS) within or immediately adjacent to the stent, necessitating reintervention in 19 patients (PTCA, $\mathrm{n}=12$; repeat $\mathrm{CABG}, \mathrm{n}=7$ ). In the group without stent-related restenosis $(n=28), 15$ patients had progression of disease in either the native or bypass vessels leading to recurrence of major anginal symptoms within 1 to 24 months. Ten of these patients required further intervention (stent, $\mathrm{n}=6$; PTCA, $n=3$; repeat $C A B G, n=1$ ). Stenting in saphenous coronary bypass grafts can be performed safely with excellent immediate angiographic and clinical results. Early occlusion, late restenosis, and bleeding complications associated with the aggressive anticoagulant treatment remain significant limitations. Reintervention as a result of restenosis or progression of disease in other lesions is common. Stenting of diseased bypass grafts in symptomatic patients with end-stage coronary artery disease (who are at high risk for conventional angioplasty or surgical reintervention) may be useful as palliative therapy.

\section{REFERENCES}

1. Schaff HV, Orzulak TA, Gersh BJ, et al. The morbidity and mortality of reoperation for coronary artery disease and analysis of late results with use of actuarial estimate of event-free interval. J Thorac Cardiovasc Surg 1983;85:508-15.

2. Lytle BW, Loop FD, Cosgrove DM, Taylor PC, Goormastic M, Peper W, Gill CC, Golding LAR, Stewart RW. Fifteen hundred coronary reoperations. Results and determinants of early and late survival. J Thorac Cardiovasc Surg 1987;93:847-59.

3. Laird-Meeter $K$, Van Domburg $R$, van den Brand $M$, Lubsen $J$, Bos E, Hugenholtz PG. Incidence, risk and outcome of reintervention after aorta coronary bypass surgery. Br Heart $\mathrm{J}$ 1987;57:427-35.

4. Meester BH, Samson M, Suryapranata H, Bonsel G, van den Brand M, de Feyter PJ, Serruys PW. Long-term follow-up after attempted angioplasty of saphenous vein grafts: the Thoraxcenter experience 1981-1988. Eur Heart J 1991;12:648-53.

5. Plokker HWT, Meester BH, Serruys PW. The Dutch experience in precutaneous transluminal angioplasty of narrowed saphenous veins used for aortocoronary arterial bypass. Am J Cardiol 1991;67:361-6.

6. de Feyter PJ, Serruys PW, van den Brand M, Meester H, Beatt $K$, Suryapranata $H$. Percutaneous transluminal angioplasty of a totally occluded venous bypass graft: a challenge that should be resisted. Am J Cardiol 1989;1:87-90.
7. Douglas JS, Gruntzig AR, King III SB, Hollman J, Ischinger T, Meier B, Craver JM, Jones EL, Waller JL, Bone DK, Guyton $R$. Percutaneous transluminal coronary angioplasty in patients with prior coronary bypass surgery. J Am Coll Cardiol 1983;2:745-54.

8. Block PC, Cowley MJ, Kaltenbach M, Kent KM, Simpson J. Percutaneous angioplasty of stenoses of bypass grafts or of bypass graft anastomosis sites. Am J Cardiol 1984;53: 666-8.

9. Corbell J, Franco I, Hollman J, Simpfendorfer C, Gaian K. Percutaneous transluminal coronary angioplasty after previous coronary artery bypass surgery. Am J Cardiol 1985;56:398403.

10. Cote G, Myler RK, Stertzer SH, Clark DA, Fishman-Rosen J, Murphy M, Shaw RE. Percutaneous transluminal angioplasty of stenotic coronary artery bypass grafts: 5 years' experience. J Am Coll Cardiol 1987;9:8-17.

11. Kussmaul WG. Percutaneous angioplasty of coronary bypass grafts: an emerging consensus. Cathet Cardiovasc Diagn 1988;15:1-4.

12. Dorros G, Lewin RF, Mathiak LM, et al. Percutaneous transluminal coronary angioplasty in patients with two or more previous coronary artery bypass grafting operations. Am J Cardiol 1988;61:1243-7.

13. Pinkerton CA, Slack JD, Orr CM. Percutaneous transluminal angioplasty in patients with prior myocardial revascularization surgery. Am J Cardiol 1988;61:15G-22G.

14. Sigwart U, Puel J, Mirkovitch V, Joffre F, Kappenberger L. Intravascular stents to prevent occlusion and restenosis after transluminal angioplasty. N Engl J Med 1987;316:701-6.

15. Serruys PW, Juilliere Y, Bertrand ME, Puel J, Richards AF, Sigwart U. Additional improvement of stenosis geometry in human coronary arteries by stenting after balloon dilatation. Am J Cardiol 1988;61:71G-6G.

16. Puel J, Juilliere Y, Bertrand ME, Rickards AF, Sigwart U, Serruys PW. Early and late assessment of stenosis geometry after coronary arterial stenting. Am J Cardiol 1988;61:546-53.

17. Urban P, Sigwart U, Golf S, Kaufmann U, Sadeghi H, Kappenberger L. Intravascular stenting for stenosis of aortocoronary venous bypass grafts. J Am Coll Cardiol 1989;13:108591.

18. Serruys PW, Beatt KJ, Van der Giessen WJ. Stenting of coronary arteries. Are we the sorcerer's apprentice? Eur Heart J 1989;10:774-82.

19. Schatz RA. A view of vascular stents. Circulation 1989;79:44557.

20. Ellis SG, Topol EJ. Intracoronary stents: will they fulfill their promise as an adjunct to angioplasty? $\mathrm{J}$ Am Coll Cardiol 1989;13:1425-30

21. King III SB. Vascular stents and atherosclerosis. Circulation 1989;79:460-2.

22. Bucx JJ, de Scheerder I, Beatt K, van den Brand M, Suryapranata $\mathrm{H}$, de Feyter PJ, Serruys PW. The importance of adequate anticuagulation to prevent early thrombosis after stenting of stenosed venous grafts. AM HEART J 1991; 121:138996.

23. Wijns W, Serruys PW, Reiber JHC, Brand M van den, Simoons ML, Kooijman CJ, Balakumaran K, Hugenholtz PG Quantitative angiography of the left anterior descending coronary artery: correlations with pressure gradient and results of exercise thallium scintigraphy. Circulation 1985;71:273-9.

24. Serruys PW, Luijten HE, Beatt KJ, Geuskens R, de Feyter PJ, van den Brand M, Reiber JHC, ten Katen HJ, van Es GA, Hugenholtz PG. Incidence of restenosis after successful angioplasty: a time related phenomenon. Circulation 1988; $77: 361-71$

25. Beatt KJ, Luyten ME, de Feyter PJ, van den Brand M, Reiber JHC, Serruys PW. Change in diameter of coronary artery seg ments adjacent to stenosis after percutaneous transluminal coronary angiography: failure of percent diameter stenosis 
measurement to reflect morphologic changes induced by balloon dilatation. J Am Coll Cardiol 1988;12:315-23.

26. Dorros G, Johnson WD, Tector AJ, Schmahl TM, Kalush SL Janke L. Percutaneous transluminal coronary angioplasty in patients with prior coronary artery bypass grafting. J Thorac Cardiovasc Surg 1984;87:17-26.

27. Campeau L, Lesperance J, Hermann J, Corbara F, Grondin CM, Bourassa MG. Loss of improvement of angina between 1 and 7 years after aortocoronary bypass surgery: correlations with changes in vein grafts and in coronary arteries. Circulation $1979 ; 60: 11-5$.

28. Brown BG, Cukingnan RA, DeRouen T, Goede LV, Wong M, Fee HJ, Roth JA, Carey JS. Improved graft patency in patients treated with platelet-inhibiting therapy after coronary bypass surgery. Circulation 1985;72:138-46.
29. Gould KL. Percent coronary stenosis: battered gold standard, pernicious relic or clinical practicality? J Am Coll Cardiol 1988;II:886-8.

30. Strauss BH, Leborgne O, de Scheerder IK, Serruys PW. Implantation of an endoluminal prosthesis at the distal anastomosis of a bypass graft for abrupt closure following balloon angioplasty. Cathet Cardiovasc Diagn 1990;21:271-4.

31. Webb JG, Myler RK, Shaw RE, Anwar A, Mayo JR, Murphy MC, Cumberland DC, Stertzer SH. Coronary angioplasty after coronary bypass surgery: initial results and late outcome in 422 patients. J Am Coll Cardiol 1990;16:812-20.

32. Goy JJ, Sigwart U, Vogt P, Stauffer JC, Kaufmann U, Urban $P$, Kappenberger L. Long-term follow-up of the first 56 patients treated with intracoronary self-expanding stent (the Lausanne experience). Am J Cardiol 1991;67:569-72. 